\title{
PERK Activation Promotes Medulloblastoma Tumorigenesis by Attenuating Premalignant Granule Cell Precursor Apoptosis
}

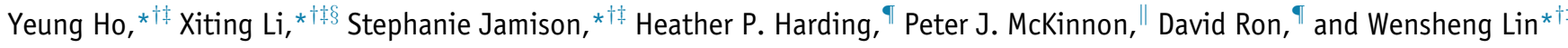 \\ From the Department of Neuroscience, $*$ the Institute for Translational Neuroscience, ${ }^{\dagger}$ and the Masonic Cancer Center ${ }^{\ddagger}$ University of Minnesota, Minneapolis, \\ Minnesota; the Department of Periodontics, ${ }^{\S}$ Guanghua School of Stomatology, Hospital of Stomatology, Sun Yat-sen University, Guangzhou, China; the \\ Cambridge Institute of Medical Research," University of Cambridge, Cambridge, United Kingdom; and the Department of Genetics," St. Jude Children's \\ Research Hospital, Memphis, Tennessee
}

\author{
Accepted for publication \\ March 4, 2016. \\ Address correspondence to \\ Wensheng Lin, M.D., Ph.D., \\ Institute for Translational \\ Neuroscience, University of \\ Minnesota, 2101 6th St. SE, \\ WMBB4-140, Minneapolis, \\ MN 55455. E-mail: linw@umn. \\ edu.
}

\begin{abstract}
Evidence suggests that activation of pancreatic endoplasmic reticulum kinase (PERK) signaling in response to endoplasmic reticulum stress negatively or positively influences cell transformation by regulating apoptosis. Patched 1 heterozygous deficient $\left(P t c h 1^{+/-}\right)$mice reproduce human Gorlin's syndrome and are regarded as the best animal model to study tumorigenesis of the sonic hedgehog subgroup of medulloblastomas. It is believed that medulloblastomas in $P t c h 1^{+/-}$mice results from the transformation of granule cell precursors (GCPs) in the developing cerebellum. Here, we determined the role of PERK signaling on medulloblastoma tumorigenesis by assessing its effects on premalignant GCPs and tumor cells. We found that PERK signaling was activated in both premalignant GCPs in young Ptch $1^{+/-}$mice and medulloblastoma cells in adult mice. We demonstrated that PERK haploinsufficiency reduced the incidence of medulloblastomas in Ptch1 $1^{+/-}$mice. Interestingly, PERK haploinsufficiency enhanced apoptosis of premalignant GCPs in young Ptch $1^{+/-}$mice but had no significant effect on medulloblastoma cells in adult mice. Moreover, we showed that the PERK pathway was activated in medulloblastomas in humans. These results suggest that PERK signaling promotes medulloblastoma tumorigenesis by attenuating apoptosis of premalignant GCPs during the course of malignant transformation. (Am J Pathol 2016, 186: 1939-1951; http://dx.doi.org/10.1016/j.ajpath.2016.03.004)
\end{abstract}

Pancreatic endoplasmic reticulum kinase (PERK) activation in response to endoplasmic reticulum (ER) stress promotes cell survival under stressful conditions through inhibition of global protein biosynthesis and induction of certain stressinduced cytoprotective genes by phosphorylating translation initiation factor $2 \alpha(\mathrm{eIF} 2 \alpha)^{1,2}$ Nevertheless, PERK activation also controls an apoptotic program to eliminate ERstressed cells. ${ }^{3,4}$ Studies found that PERK activation induced by hypoxia and nutritional deficiency, hallmarks of the solid tumor microenvironment, influences tumor development by regulating tumor cell viability, tumor invasion, and angiogenesis. $^{5-8}$ However, because of the double-edged sword nature of PERK signaling, the data about its role, promoting or inhibiting, in tumor development are contradictory. ${ }^{9,10}$ It is well documented that apoptosis serves as a natural barrier to malignant transformation. Cell transformation requires concomitant activation of unrestricted cell proliferation and suppression of apoptosis. ${ }^{11,12}$ Interestingly, recent reports suggest that PERK signaling participates in cell transformation by regulating apoptosis. ${ }^{13,14}$ A report found that PERK activation promotes Myc-dependent malignant transformation by attenuating cell apoptosis. ${ }^{13}$ In contrast, another report found that PERK activation suppresses malignant transformation by enhancing cell apoptosis. ${ }^{15}$

Medulloblastoma is the most common solid malignancy of childhood. ${ }^{16}$ From gene expression profiling, medulloblastoma

\footnotetext{
Supported by NIH grants NS073132 (W.L.) and NS37956 and CA21765 (P.J.M.), National Multiple Sclerosis Society grants RG4813-A-2 and RG5239-A-3 (W.L.), Wellcome Trust grant 084812 (D.R.), and ALSAC Foundation (P.J.M.).

Y.H. and X.L. contributed equally to this work.

Disclosures: None declared.
} 
can be divided into four discrete molecular subgroups: sonic hedgehog (SHH) subgroup, WNT subgroup, subgroup 3, and subgroup $4 .{ }^{17,18}$ Although multiple genetic mutations that drive sustained cell proliferation are documented in medulloblastoma, ${ }^{17-19}$ the mechanisms that regulate cell apoptosis during malignant transformation remain unclear. Mice heterozygous for Patchedl (Ptch1 $\left.{ }^{+-}\right)$, a SHH receptor, recapitulate human Gorlin's syndrome and are regarded as the best animal model to study tumorigenesis of the $\mathrm{SHH}$ subgroup of medulloblastomas..$^{20,21}$ Medulloblastoma in $P t c h 1^{+/-}$mice arises from granule cell precursors (GCPs) in the external granular layer (EGL) of the developing cerebellum and shows distinct steps of progression. ${ }^{22-24}$ These mice have hyperplastic lesions that contain premalignant GCPs in the EGL as late as 6 weeks of age. Most hyperplastic lesions regress; however, a few hyperplastic lesions undergo malignant transformation and progress to medulloblastoma.

Mutations of Perk (also known as Eif2ak3) were observed in human medulloblastoma. A report found that 7 of 35 human medulloblastomas exhibit Perk mutations. ${ }^{25}$ Our previous in vitro study found that PERK activation facilitates human medulloblastoma cell migration and invasion through induction of vascular endothelial growth factor A (VEGF-A). ${ }^{26}$ The report also found that PERK inactivation suppresses human medulloblastoma cell migration and invasion. ${ }^{26}$ Moreover, a study found that ER stress responsive genes are up-regulated in premalignant GCPs in young Ptch $1^{+/-}$mice. $^{22}$ Thus, we sought to elucidate the impact of the PERK branch of the ER stress response on the development of medulloblastoma. In this study, we confirmed PERK activation in human medulloblastoma and reported that PERK activation facilitated medulloblastoma development in Ptchl $^{+/-}$mice by attenuating premalignant GCP apoptosis. PERK haploinsufficiency reduced the incidence of medulloblastomas in $P t c h 1^{+/-}$mice, which was associated with increased apoptosis of premalignant GCPs in young mice. Surprisingly, PERK haploinsufficiency had a minimal effect on medulloblastoma cells in adult $\mathrm{Ptch}^{+/-}$mice.

\section{Materials and Methods}

\section{Generation of Mice}

Ptch $^{+/-}$mice $^{20}$ on a mixed C57BL/6 $\times 129$ Sv background were purchased from The Jackson Laboratory (Bar Harbor, ME). Ptch ${ }^{+/-}$mice were crossed with Perk heterozygous deficient $\left(\right.$ Perk $\left.^{+/-}\right)$mice $^{27}$ on the C57BL/6 background to obtain Ptchl $^{+/-} ;$Perk $^{+/+}$mice and PtchI ${ }^{+/-} ;$Perk $^{+/-}$ mice. Genotypes were determined by PCR from the DNA extracted from tail tips. The following primers were used for PCR amplification: PJ1 (5'-ACAAGAAAGCAGAGTCCGGG-3') and PJ2 (5'-GTCACGACGTTGTAAAACGAC- $\left.3^{\prime}\right)$ for Ptchl $^{+/-}$mice genotyping; 1740S (5'-AAGGACCCTATCCTCCTGCTGCAC-3'), PGK.255R (5'-GCTACCGGTGGATGTGGAATGTG-3'), and i.6AS (5'-CGGAGACAGTACAAGCGCAGATGA-3') for Perk $^{+/-}$mice genotyping.
Mice were monitored daily to detect medulloblastoma phenotypes, including ataxia, decreased movement, poor grooming, and doming of the skull, until the age of 8 months. All animal procedures were conducted in complete compliance with the NIH's Guide for the Care and Use of Laboratory Animals ${ }^{28}$ and were approved by the Institutional Animal Care and Use Committee of the University of Minnesota.

\section{Histology, Immunohistochemistry, and TUNEL Staining}

Adult mice with medulloblastoma phenotypes and all 8-month-old asymptomatic mice received an intraperitoneal injection of $100 \mathrm{mg} / \mathrm{kg}$ bromodeoxyuridine (BrdU; SigmaAldrich, St. Louis, MO) 2 hours before perfusion. Six-weekold asymptomatic mice received a BrdU injection 8 hours before perfusion. Anesthetized mice were perfused through the left cardiac ventricle with $4 \%$ paraformaldehyde in 0.1 $\mathrm{mol} / \mathrm{L}$ phosphate buffer. Brains were bisected in the sagittal plane, and one-half was postfixed for at least 48 hours in $4 \%$ paraformaldehyde in phosphate-buffered saline, dehydrated through graded alcohols, and embedded in paraffin. Serial sections of $5-\mu \mathrm{m}$ thickness were cut, and every 10th section in the series was routinely stained with hematoxylin and eosin (H\&E). The other half of the brain was postfixed for 1 hour in $4 \%$ paraformaldehyde in phosphate-buffered saline, cryopreserved in $30 \%$ sucrose for 48 hours, embedded in OCT compound, and frozen on dry ice. Frozen sections were cut in a cryostat at $10-\mu \mathrm{m}$ thickness. Immunohistochemistry (IHC) for NeuN (dilution 1: 200; Millipore, Temecula, CA), proliferating cell nuclear antigen (PCNA; dilution 1:50,000; Sigma-Aldrich), phosphorylated PERK (p-PERK; dilution 1:100; Santa Cruz Biotechnology, Santa Cruz, CA), glial fibrillary acidic protein (dilution 1:1000; Covance, Princeton, NJ), synaptophysin (dilution 1:200; Millipore), VEGF-A (dilution 1:50; Santa Cruz Biotechnology), active-caspase 3 (dilution 1:200; Cell Signaling Technology, Danvers, MA), p53 (dilution 1:100; Santa Cruz Biotechnology), and p53 up-regulated modulator of apoptosis (PUMA; dilution 1:100; Santa Cruz Biotechnology) were performed on paraffin sections. IHC for CD31 (dilution 1:50; Santa Cruz Biotechnology) was performed on cryosections. All primary antibodies, with the exception of p53 and PUMA antibodies, were detected with the Vectastain ABC kits (Vector Laboratories, Burlingame, CA) and $3^{\prime} 5^{\prime}$-diaminobenzidine $/ \mathrm{H}_{2} \mathrm{O}_{2}$ reagent (Vector Laboratories) as substrate. p53 and PUMA antibodies were detected with the fluorescein-labeled secondary antibody (Vector Laboratories). Fluorescent-stained sections were mounted with Vectashield mounting medium with DAPI (Vector Laboratories) and visualized with the Zeiss Axioskop 2 microscope (Carl Zeiss GmbH, Jena, Germany).

Terminal deoxynucleotidyl transferase-mediated biotinylated UTP nick end labeling (TUNEL) staining was performed on paraffin sections with the use of the ApopTag kit (Millipore) according to the manufacturer's instructions. 
IHC for BrdU (dilution 1:1000; Sigma-Aldrich) was performed on paraffin sections as described previously. ${ }^{29,30} \mathrm{We}$ quantified positive cells for BrdU, TUNEL, and VEGF-A and for $\mathrm{CD}_{3} 1^{+}$blood vessels in the center of medulloblastoma or hyperplastic lesions in the cerebellum as described previously. ${ }^{29,30}$

\section{Western Blot Analysis}

Cerebellar tissues were removed from adult control wild-type (WT) mice and adult symptomatic Ptchl ${ }^{+/-} ;$Perk $^{+/+}$mice and Ptchl $^{+/-}$; Perk ${ }^{+/-}$mice, which displayed typical medulloblastoma clinical phenotypes and enlarged cerebellum. These tissues were homogenized in 5 volumes of Triton X100 buffer with the use of a motorized homogenizer as previously described. ${ }^{31-33}$ After incubation on ice for $15 \mathrm{mi}-$ nutes, the extracts were cleared by centrifugation at $18,000 \times \mathrm{g}$ for 30 minutes twice. The protein concentration of each extract was determined by DC Protein Assay (Bio-Rad Laboratories, Hercules, CA). The extracts $(120 \mu \mathrm{g})$ were separated by SDSPAGE and transferred to nitrocellulose membranes. The blots were then incubated with primary antibodies to p-PERK (dilution 1:1000; Santa Cruz Biotechnology), p-eIF2 $\alpha$ (dilution 1:1000; Cell Signaling Technology), eIF2 $\alpha$ (dilution 1:1000; Santa Cruz Biotechnology), and actin (dilution 1:5000; Sigma-Aldrich), followed by the horseradish peroxidaseconjugated secondary antibody (Vector Laboratories). The chemiluminescent signal was detected by the ECL Detection Reagents (GE Healthcare Biosciences, Piscataway, NJ). The intensity of the recorded chemiluminescence signal was quantified with the ImageQuantTL LAS4000 software version 1.2 from GE Healthcare Life Sciences.

\section{TaqMan Real-Time PCR}

Cerebellar tissues were removed from adult control WT mice and adult symptomatic Ptchl $^{+/-} ;$Perk $^{+/+}$mice and Ptchl $^{+/-}$; Perk $^{+/-}$mice, which displayed typical medulloblastoma clinical phenotypes and enlarged cerebellum. RNA was isolated from the cerebellum with the use of TRIzol reagent (Invitrogen, Carlsbad, CA) and was treated with DNase I (Invitrogen) to eliminate genomic DNA. Reverse transcription was performed with the iScript cDNA Synthesis Kit (Bio-Rad Laboratories). TaqMan real-time PCR was performed with iQ Supermix (Bio-Rad Laboratories) on the LightCycler 480 System (Roche Diagnostics Corporation, Indianapolis, IN) as described previously. ${ }^{26,29,31}$

\section{Human Medulloblastoma Samples and IHC}

Paraffin-embedded human medulloblastoma sections $(5-\mu \mathrm{m}$ thickness) and brain sections from individuals without brain tumor were provided by Brain Tumor Tissue Bank (London, ON, Canada), including six cases of pediatric medulloblastoma, three cases of adult medulloblastoma, and three nontumor brain tissue samples. IHC for p-PERK and CAATT enhancer binding protein homologous protein (CHOP; dilution 1:100; Thermo Scientific, Grand Island, NY) was performed as described in Histology, Immunohistochemistry, and TUNEL Staining. The degree of positive staining for p-PERK was determined by using a semiquantitative staining index $=$ intensity $\times$ distribution. The intensity of cytoplasmic staining detected by IHC was scored on a scale of 0 to 4 : $0=$ negative staining, $1=$ weak staining, $2=$ modest staining, $3=$ moderate staining, and $4=$ strong staining. The distribution was scored on a scale of 1 to 4 from the percentage of cells with any level of staining: $1=1 \%$ to $25 \%$ positive cells, $2=26 \%$ to $50 \%$ positive cells, $3=51 \%$ to $75 \%$ positive cells, and $4=76 \%$ to $100 \%$ positive cells.

\section{Statistical Analysis}

Data are expressed as means \pm SD. Comparisons between two groups were statistically evaluated by Student's $t$-test with the use of GraphPad Prism software version 6 (GraphPad Software Inc., La Jolla, CA). The incidence of symptomatic medulloblastoma between Ptchl $^{+/} ;$Perk $^{+/+}$ mice and Ptch $^{+/-} ;$Perk $^{+/-}$mice was statistically evaluated by Kaplan-Meier analysis and the incidence of total medulloblastoma between these two groups was statistically evaluated by $\chi^{2}$ test with the use of Prism 6 (GraphPad). $P<0.05$ was considered significant.

\section{Results}

\section{PERK Activation in Human Medulloblastoma}

During ER stress, PERK is activated through oligomerization and autophosphorylation, which coordinates an adaptive program by phosphorylating eIF $2 \alpha$ at serine $51 .{ }^{1}$ To assess the potential relevance of previous observations of the enhanced expression of ER stress responsive genes in mouse models of medulloblastoma, ${ }^{22,29}$ we estimated the level of PERK activity in human medulloblastoma by p-PERK IHC. As expected, immunoreactivity of p-PERK was undetectable in nontumor brain tissues (Figure 1A). Interestingly, a number of tumor cells were positive for p-PERK in clinical samples of pediatric medulloblastoma (Figure 1B, Table 1), and the p-PERK IHC signal was also markedly increased in the tumor cells in adult medulloblastoma (Figure 1C, Table 1). Moreover, semiquantitative analysis confirmed that PERK was activated in medulloblastoma in all six cases of pediatric patients and three cases of adult patients (Table 1). However, the intensity and distribution of p-PERK staining in human medulloblastoma were variable, which likely reflects the heterogeneity of human tumor. In addition, IHC for CHOP, a PERK-responsive gene, found that immunoreactivity of CHOP was undetectable in nontumor brain tissues (Figure 1D), but it became detectable in a number of tumor cells in both pediatric and adult medulloblastomas (Figure 1, $\mathrm{E}$ and $\mathrm{F}$ ). Taken together, our data suggest that PERK signaling is enhanced in human medulloblastoma, prompting an enquiry into its potential pathophysiologic significance. 

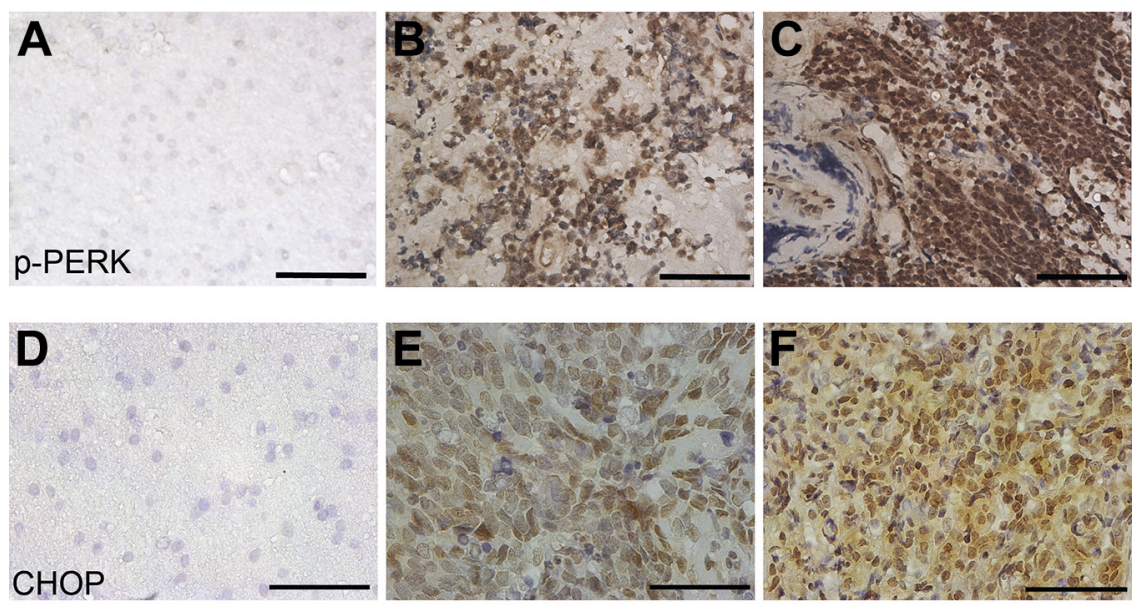

Figure 1 Activation of PERK signaling in human medulloblastoma. A: p-PERK IHC found that immunoreactivity of $\mathrm{p}$-PERK was undetectable in nontumor brain tissues. B: A representative image from pediatric medulloblastoma 5 in Table 1 shows that a number of tumor cells are positive for p-PERK in pediatric medulloblastoma. C: A representative image from adult medulloblastoma 1 in Table 1 shows that the level of p-PERK is markedly increased in the tumor cells in adult medulloblastoma. D: Immunoreactivity of CHOP was undetectable in nontumor brain tissues. E: Many tumor cells were positive for CHOP in pediatric medulloblastoma. F: Many tumor cells were positive for CHOP in adult medulloblastoma. $n=3$ patients $(\mathbf{A}, \mathbf{C}, \mathbf{D}, \mathbf{F}) ; n=6$ patients (B and E). Scale bar $=$ $50 \mu \mathrm{m}$. CHOP, CAATT enhancer binding protein homologous protein; IHC, immunohistochemistry; p-, phosphorylated; PERK, pancreatic endoplasmic reticulum kinase.

\section{PERK Activation in Medulloblastoma Cells in Adult Ptch $1^{+/-}$Mice and in Premalignant GCPs in Young Mice}

Medulloblastomas in $\mathrm{Ptchl}^{+/-}$mice arises from the cerebellar GCPs in the EGL. ${ }^{34,35}$ During early postnatal development, GCPs proliferate, differentiate, and migrate to their final destination, the internal granule layer. In normal mice, by postnatal day 21 , this process is complete, and there are no GCPs in the EGL. In contrast, Ptchl $^{+/-}$mice have abnormal patches of premalignant GCPs in the EGL of the cerebellum at the age of 3 weeks. ${ }^{22,36}$ By the age of 6 weeks, these mice have focal hyperplastic lesions or diffuse hyperplastic lesions that contain premalignant GCPs in the cerebellum. These hyperplastic lesions either undergo malignant transformation and progress to medulloblastoma or regress over time. ${ }^{22,24,37} \mathrm{H} \& \mathrm{E}$ staining revealed typical medulloblastoma in the cerebellum of adult $P t c h 1^{+/-}$mice that displayed medulloblastoma clinical phenotypes (Figure 2B) and typical hyperplastic lesions in the EGL in the cerebellum of 6-week-old Ptchl ${ }^{+/-}$mice (Figure 2D) compared with the normal cerebellum of age-matched WT mice (Figure 2, A and $\mathrm{C}$ ).

Table 1 Semiquantitative Analysis of p-PERK IHC

\begin{tabular}{lllll}
\hline $\begin{array}{l}\text { Medulloblastoma } \\
\text { sample }\end{array}$ & $\begin{array}{l}\text { Patient } \\
\text { age }\end{array}$ & $\begin{array}{l}\text { Patient } \\
\text { sex }\end{array}$ & $\begin{array}{l}\text { Staining } \\
\text { intensity }\end{array}$ & $\begin{array}{l}\text { Staining } \\
\text { distribution }\end{array}$ \\
\hline Pediatric 1 & $\begin{array}{c}\text { 11 years } \\
\text { Pediatric 2 }\end{array}$ & Female & 2 & 2 \\
Pediatric 3 & 3 years & Male & 2 & 1 \\
Pediatric 4 & Female & 1 & 1 \\
Pediatric 5 & 6 years & Male & 1 & 1 \\
Pediatric 6 & 7 months & Male & 3 & 3 \\
Adult 1 & 32 years & Male & 1 & 1 \\
Adult 2 & 30 years & Male & 3 & 4 \\
Adult 3 & 39 years & Female & 2 & 4 \\
\hline
\end{tabular}

IHC, immunohistochemistry; p-PERK, phosphorylated pancreatic endoplasmic reticulum kinase.
To investigate the role of PERK signaling in medulloblastoma tumorigenesis, we determined the activity of PERK signaling in medulloblastoma cells and premalignant GCPs in $P t c h 1^{+/-}$mice. Similar to our finding in human medulloblastoma samples (see Perk Activation in Human Medulloblastoma), p-PERK IHC found that the immunoreactivity of p-PERK was undetectable in cells in the cerebellum of adult WT mice (Figure 2E), but it became detectable in a number of medulloblastoma cells in adult $\mathrm{Ptchl}^{+/-}$mice (Figure 2F). Western blot analysis also found that the levels of p-PERK and p-eIF $2 \alpha$ were significantly increased in the cerebellum of adult $\mathrm{PtchI}^{+/-}$mice with medulloblastomas compared with adult WT mice (Figure 2, I and J). Although real-time PCR analysis found comparable levels of PERK mRNA in the cerebellum of adult WT mice and Ptch1 ${ }^{+/-}$ mice with medulloblastomas, the mRNA levels of $\mathrm{CHOP}$ and growth arrest and DNA damage 34 (GADD34), target genes of the PERK-eIF $2 \alpha$ pathway, were significantly increased in the cerebellum of adult PtchI ${ }^{+/-}$mice with medulloblastomas compared with adult WT mice (Figure 2K). Moreover, consistent with a previous report indicating that the levels of ER stress responsive genes were elevated in premalignant GCPs in hyperplastic lesions in 6-week-old Ptch1 ${ }^{+/-}$mice, ${ }^{22}$ p-PERK IHC found that the immunoreactivity of p-PERK was undetectable in the cerebellar cells of 6-week-old WT mice (Figure 2G) but became detectable in a number of premalignant GCPs in hyperplastic lesions in $P t c h 1^{+/-}$mice (Figure 2H). Taken together, these data indicate that PERK signaling is activated in both premalignant GCPs and medulloblastoma cells in $P t c h 1^{+/-}$mice, suggesting its potential role in tumorigenesis.

\section{PERK Haploinsufficiency Reduces the Incidence of Medulloblastomas in Ptch $1^{+/-}$Mice}

Ptchl $^{+/-}$mice develop symptomatic medulloblastomas typically between the ages of 8 and 35 weeks. ${ }^{21,38}$ Perk 

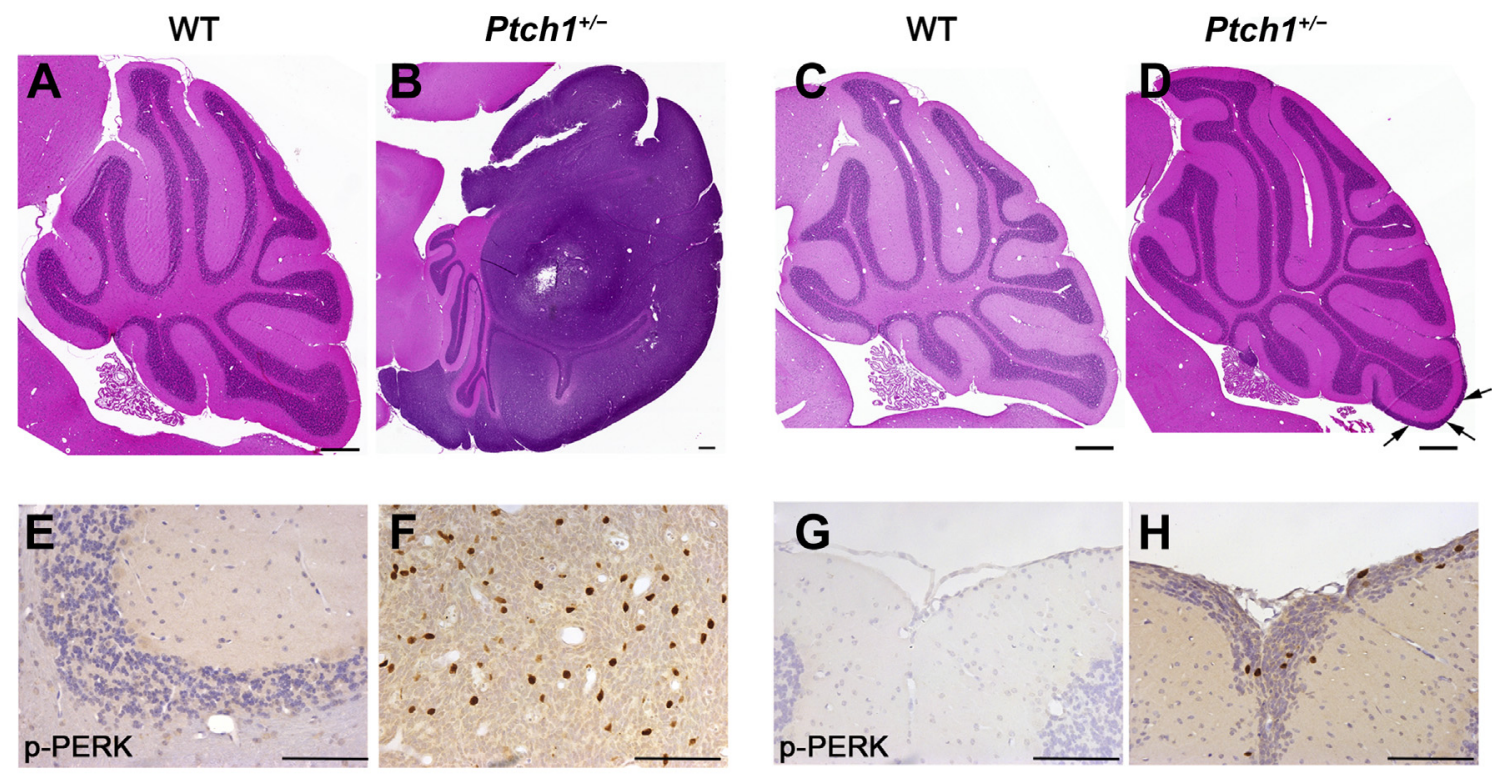

I
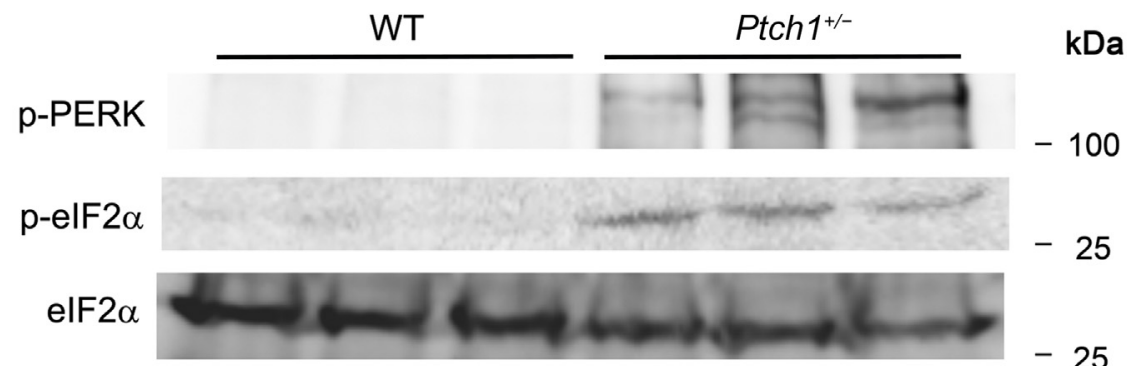

Actin
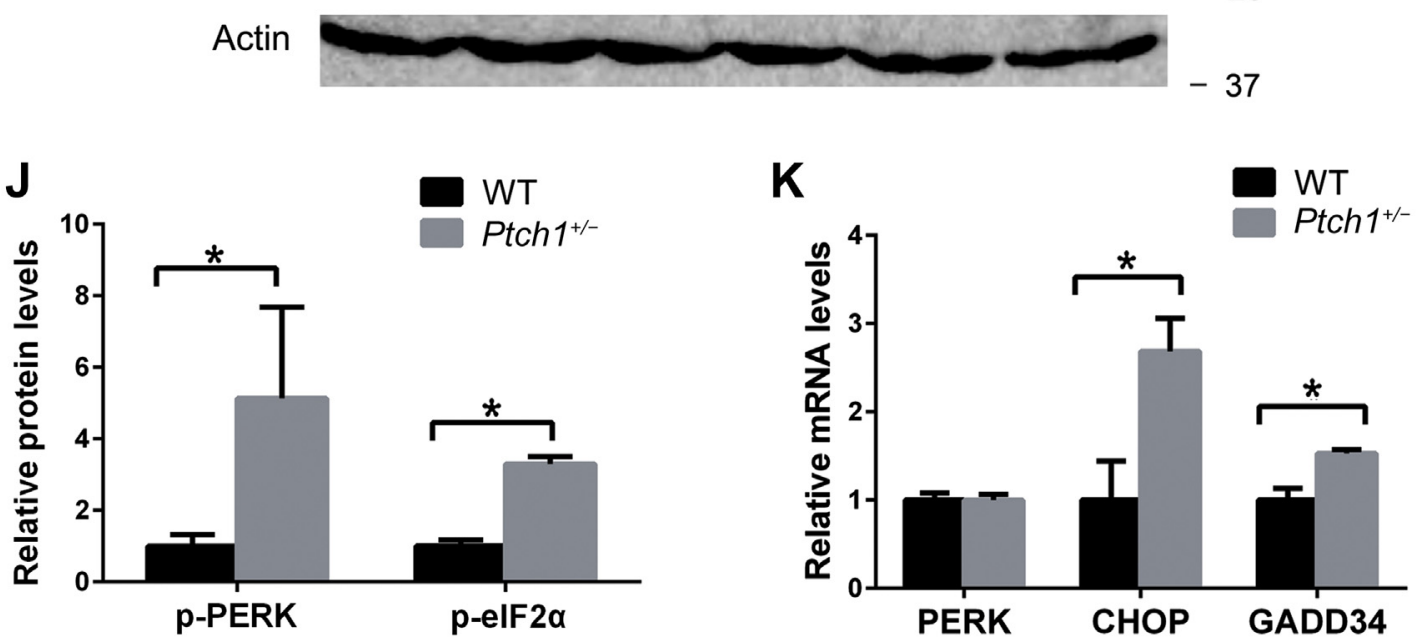

Figure 2 Activation of PERK signaling in both hyperplastic lesions and medulloblastomas in the cerebellum of Ptch1 ${ }^{+/-}$mice. A-D: H\&E staining revealed a normal cerebellum in adult WT mice (A), a medulloblastoma in the cerebellum of adult Ptch1 $1^{+/-}$mice (B), a normal cerebellum in 6-week-old WT mice (C), and a hyperplastic lesion (arrow) in the cerebellar EGL of 6 -week-old Ptch $1^{+/-}$mice (D). E and F: p-PERK IHC found that p-PERK is undetectable in cells in the cerebellum of adult WT mice but became detectable in a number of cells in medulloblastomas in adult Ptch $1^{+/-}$mice. $\mathbf{G}$ and $\mathbf{H}$ : $p$-PERK IHC found that $p$-PERK was undetectable in cells in the cerebellum of 6 -week-old WT mice but became detectable in a number of cells in hyperplastic lesions in the cerebellar EGL of 6-week-old Ptch $1^{+/-}$mice. I and J: Western blot analysis found significantly increased levels of p-PERK and p-eIF2 $\alpha$ in the cerebellum of adult Ptch $1^{+/-}$mice with medulloblastomas compared with adult WT mice. K: Real-time PCR analysis found that the mRNA level of PERK in the cerebellum of adult Ptch ${ }^{+/-}$mice with medulloblastomas was comparable with adult WT mice and that the mRNA levels of CHOP and GADD34 were significantly increased in the cerebellum of adult $P$ tch $1^{+/-}$mice with medulloblastomas compared with adult WT mice. Data are expressed as means \pm SD. $n=3$ animals. ${ }^{*} P<0.05$. Scale bars: $1000 \mu \mathrm{m}$ $(\mathbf{A}-\mathbf{D}) ; 100 \mu \mathrm{m}(\mathbf{E}-\mathbf{H})$. CHOP, CAATT enhancer binding protein homologous protein; EGL, external granular layer; eIF2 $\alpha$, translation initiation factor $2 \alpha$; GADD34, growth arrest and DNA damage 34; H\&E, hematoxylin and eosin; IHC, immunohistochemistry; p-, phosphorylated; PERK, pancreatic endoplasmic reticulum kinase; WT, wild-type. 


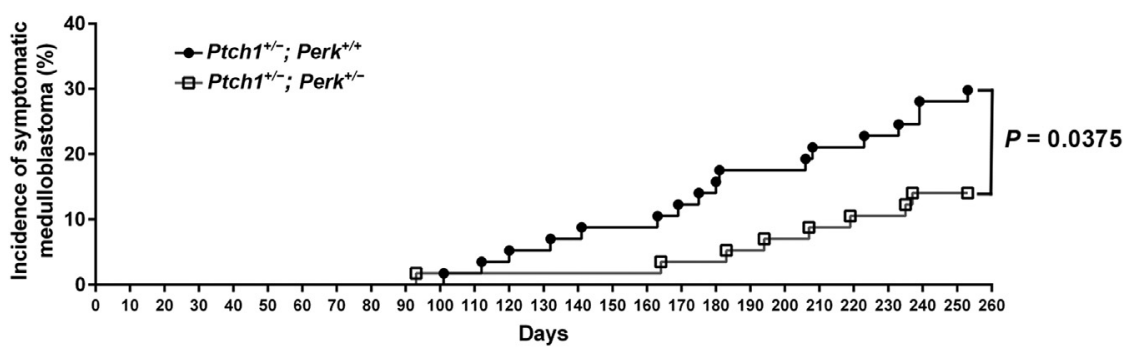

Figure 3 PERK heterozygous deficiency reduced the incidence of symptomatic medulloblastomas in $P$ tch $1^{+/-}$mice. The percentage of mice that developed symptomatic medulloblastoma. $n=57$ animals. PERK, pancreatic endoplasmic reticulum kinase.

homozygous-deficient mice die prematurely because of progressive diabetes and exocrine pancreatic deficiency. ${ }^{27}$ Perk heterozygous-deficient $\left(\right.$ Perk $\left.^{+/-}\right)$mice appear healthy but display evidence of haploinsufficiency. ${ }^{32,39,40}$ Importantly, it was found that Perk $^{+/-}$mice do not display any abnormalities in the central nervous system under normal conditions. $^{39-41}$ Therefore, we used Perk $^{+/-}$mice to determine the impact of PERK signaling on medulloblastoma tumorigenesis in $P t c h 1^{+/-}$mice. Ptch $1^{+/-}$mice were crossed with Perk $^{+/-}$mice to obtain Ptchl ${ }^{+/-} ;$Perk $^{+/+}$ mice and Ptchl ${ }^{+/-} ;$Perk $^{+/-}$mice. These mice were monitored daily up to 8 months to detect medulloblastoma phenotypes, including ataxia, decreased movement, poor grooming, and doming of the skull. Medulloblastoma formation in symptomatic mice was verified by gross examination, namely assessing enlargement of the cerebellum, and by $H \& E$ staining. We found that the frequency of symptomatic medulloblastomas in Ptchl $^{+/-}$; Perk ${ }^{+/-}$mice was significantly reduced compared with Ptchl $^{+/-} ;$Perk $^{+/+}$ mice (8 of 57 Ptchl $^{+/-}$; Perk ${ }^{+/-}$mice versus 17 of 57 Ptch1 ${ }^{+/-} ;$Perk ${ }^{+/+}$mice; $P=0.0375$ ) (Figure 3). Moreover, necropsy was performed on all 8-month-old asymptomatic Ptch1 ${ }^{+/-} ;$Perk $^{+/+}$and Ptch1 ${ }^{+/-} ;$Perk $^{+/-}$mice. Gross examination and H\&E staining revealed that 3 of 49 asymptomatic Ptch1 ${ }^{+/-}$; Perk $^{+/-}$mice and 3 of 40 asymptomatic Ptchl ${ }^{+/-} ;$Perk $^{+/+}$mice had medulloblastomas, respectively. Consistent with the previous studies, ${ }^{22,24}$ we did not find any hyperplastic lesions in the cerebellar EGL of 8-month-old Ptch1 ${ }^{+/-}$; Perk ${ }^{+/+}$mice or Ptchl ${ }^{+/-}$; Perk ${ }^{+/-}$ mice. Thus, PERK heterozygous deficiency significantly decreased the incidence of medulloblastomas in $\mathrm{Ptchl}^{+/-}$ mice (11 of 57 Ptchl $^{+/-}$; Perk ${ }^{+/-}$mice versus 20 of 57 Ptchl $^{+/-} ;$Perk $^{+/+}$mice; $\left.P=0.0457\right)$.

We further determined whether PERK heterozygous deficiency impaired the activity of PERK signaling in medulloblastoma cells in $P t c h 1^{+/-}$mice. p-PERK IHC found that the immunoreactivity of p-PERK was noticeably decreased in medulloblastomas in $\mathrm{Ptchl}^{+/-} ; \mathrm{Perk}^{+/-}$mice compared with Ptch1 ${ }^{+/-}$; Perk ${ }^{+/+}$mice (Figure 4, C and D). Moreover, Western blot analysis found that the levels of p-PERK and p-eIF2 $\alpha$ were significantly decreased in the cerebellum of Ptch1 ${ }^{+/-} ;$Perk $^{+/-}$mice with medulloblastomas compared with Ptchl $^{+/-} ;$Perk $^{+/+}$mice (Figure 4, E and F). As expected, real-time PCR analysis found that the level of PERK mRNA was reduced by approximately one-half in the cerebellum of $\operatorname{Ptch}^{+/-} ;$Perk $^{+/-}$mice with medulloblastomas compared with $\mathrm{Ptchl}^{+/-} ; \mathrm{Perk}^{+/+}$mice (Figure 4G). Moreover, real-time PCR analysis found that PERK heterozygous deficiency significantly reduced the expression of CHOP and GADD34 in the cerebellum of $\mathrm{Ptchl}^{+/-}$mice with medulloblastomas (Figure 4G). Taken together, these results indicate that PERK haploinsufficiency reduces the incidence of medulloblastomas in $P t c h 1^{+/-}$mice, likely through reduced PERK-mediated eIF2 $\alpha$ phosphorylation.

Next, we determined the effects of PERK haploinsufficiency on cell proliferation, cell apoptosis, and angiogenesis in medulloblastomas in $\mathrm{Ptchl}^{+/-}$mice. H\&E staining indicated that the structural characteristics of medulloblastomas in $\mathrm{Ptchl}^{+/-} ; \mathrm{Perk}^{+/-}$mice was comparable with Ptchl $^{+/-}$; Perk ${ }^{+/+}$mice (Figure 4, A and B). IHC for glial fibrillary acidic protein and synaptophysin found that the expression pattern of both glial fibrillary acidic protein and synaptophysin in medulloblastomas in $P t c h 1^{+/-}$; Perk $^{+/-}$mice was comparable with Ptchl $^{+/-} ;$Perk $^{+/+}$mice (Figure 5, A-D). BrdU labeling (Figure 5, E, F, and M) and PCNA IHC (data not shown) found that PERK heterozygous deficiency did not significantly change the number of proliferating cells in medulloblastomas in $\mathrm{Ptchl}^{+/-}$mice. Moreover, TUNEL staining found that PERK heterozygous deficiency had no significant effect on cell apoptosis in medulloblastomas in Ptchl $^{+/-}$mice (Figure 5, G, H, and M). A number of studies suggest that activation of PERK signaling enhances angiogenesis in tumors, including medulloblastoma, by induction of VEGF-A. ${ }^{29,42}$ Surprisingly, VEGF-A IHC found that PERK heterozygous deficiency did not significantly alter VEGF-A expression in medulloblastomas in $P t c h 1^{+/-}$mice (Figure 5, I, J, and M), and CD31 IHC found that PERK heterozygous deficiency did not significantly change angiogenesis in this tumor (Figure 5, K, L, and N). Collectively, these data suggest that PERK haploinsufficiency has a minimal effect on cell proliferation, cell apoptosis, and angiogenesis in medulloblastomas in adult Ptchl $^{+/-}$mice. Thus, it is unlikely that PERK haploinsufficiency impairs medulloblastoma formation in $\mathrm{Ptchl}^{+/-}$mice through its effects on tumor cells.

PERK Haploinsufficiency Increases Premalignant GCPs Apoptosis in the Cerebellum of Young Ptch1 ${ }^{+/-}$Mice

Evidence is emerging that PERK signaling influences tumorigenesis by regulating cell apoptosis during the course 

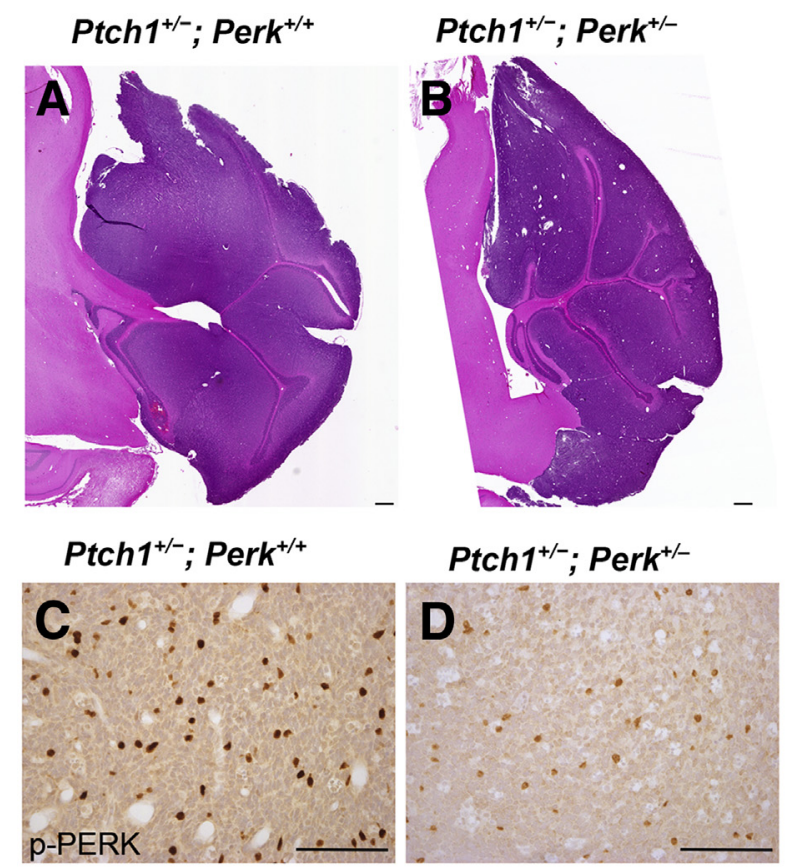

Ptch1 $^{+/-} ;$Perk $^{+/}$
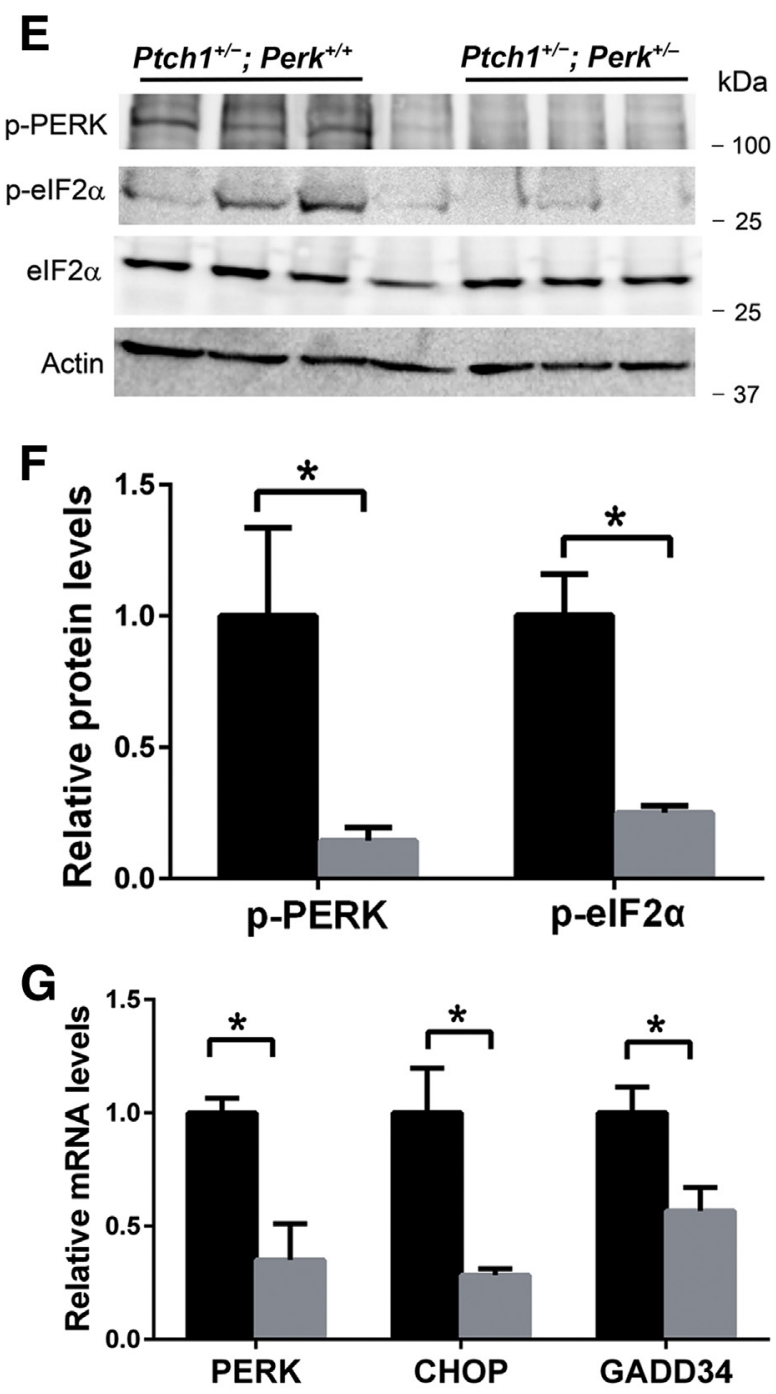

$\longrightarrow$ Ptch $^{+/-} ;$Perk $^{+/+} \square$ Ptch1 $^{+/-} ;$Perk $^{+/-}$ of malignant transformation. ${ }^{13,15,43}$ Medulloblastoma tumorigenesis in the cerebellum of $P t c h 1^{+/-}$mice found distinct steps of progression; first, focal hyperplastic lesions develop in the EGL; second, diffuse hyperplastic lesions form in the EGL and molecular layer; finally, medulloblastoma arises. $^{23,24,37}$ Previous reports found that both focal hyperplastic lesions and diffuse hyperplastic lesions can be observed in the cerebellum of $\mathrm{Ptchl}^{+/-}$mice as late as 6 weeks of age. ${ }^{22,24}$ The diffuse hyperplastic lesions are reversible and represent the final step in the process of malignant transformation, in which premalignant GCPs either gain additional genetic mutations or epigenetic changes to become irreversible tumor cells, or undergo regression. . $^{37,44}$ Therefore, we determined the effects of PERK haploinsufficiency on the proliferation and apoptosis of premalignant GCPs in diffuse hyperplastic lesions in the cerebellum of 6-week-old Ptch1 ${ }^{+/-}$mice.

We serially sectioned whole paraffin-embedded halfcerebellum of 6-week-old mice, each half-cerebellum yielded approximately 210 sections $5-\mu \mathrm{m}$ thick. Every 10th section in the series was either stained by $\mathrm{H} \& \mathrm{E}$ or immunostained by the NeuN antibody or PCNA antibody. Focal hyperplastic lesions, which contained $>10$ premalignant GCPs that were negative for NeuN (a marker of mature neurons) and positive for PCNA, were observed in the cerebellum of Ptch1 $^{+/-} ;$Perk $^{+/+}$mice (Supplemental Figure S1, A, C, and E) and $P t c h 1^{+/-} ;$Perk $^{+/-}$mice (Supplemental Figure S1, B, D, and F). Moreover, both PtchI $^{+/-}$; Perk ${ }^{+/+}$mice and Ptch1 $^{+/-} ;$Perk $^{+/-}$mice had diffuse hyperplastic lesions in the cerebellum (Supplemental Figure S1, G-L), which contained a thick layer ( $>15$ cell layers) of NeuN-negative and PCNA-positive premalignant GCPs diffusing in the EGL and molecular layer. We found, however, that the number of total hyperplastic lesions in the cerebellum of 6-week-old Ptch1 ${ }^{+/-}$; Perk ${ }^{+/-}$mice was comparable with Ptchl $^{+/-} ;$Perk $^{+/+}$mice (Figure 6A). Similarly, we found that PERK heterozygous deficiency did not reduce the number of diffuse hyperplastic lesions in the cerebellum of 6-week-old $\mathrm{Ptchl}^{+/-}$mice (Figure 6B and Figure 7, A and B).

p-PERK IHC found that immunoreactivity of p-PERK was noticeably decreased in diffuse hyperplastic lesions in

Figure 4 PERK heterozygous deficiency attenuated the activity of PERK signaling in medulloblastomas in adult $P$ tch $1^{+/-}$mice. A and B: H\&E staining found that PERK heterozygous deficiency did not change the structural characteristics of medulloblastomas in adult Ptch $1^{+/-}$mice. C and D: p-PERK IHC found noticeably decreased immunoreactivity of $\mathrm{p}$-PERK in medulloblastomas in adult Ptch1 ${ }^{+/-}$; Perk ${ }^{+/-}$mice compared with Ptch $1^{+/-} ;$Perk ${ }^{+/+}$mice. E and F: Western blot analysis found significantly decreased levels of p-PERK and p-eIF2 $\alpha$ in the cerebellum of adult Ptch1 $1^{+/}$ ${ }^{-}$; Perk ${ }^{+/-}$mice with medulloblastomas compared with Ptch $^{+/-}$; Perk $^{+/+}$ mice. G: Real-time PCR analysis found that the mRNA levels of PERK, CHOP, and GADD34 were significantly decreased in the cerebellum of $P$ tch1 ${ }^{+/-}$; $\mathrm{Perk}^{+/-}$mice with medulloblastomas compared with $\mathrm{Ptch1}^{+/-}$; Perk ${ }^{+/+}$ mice. Data are expressed as means \pm SD. $n=3$ animals. ${ }^{*} P<0.05$. Scale bars: $1000 \mu \mathrm{m}$ (A and B); $100 \mu \mathrm{m}$ (C and D). CHOP, CAATT enhancer binding protein homologous protein; eIF2 $\alpha$, translation initiation factor $2 \alpha$; GADD34, growth arrest and DNA damage 34; H\&E, hematoxylin and eosin; IHC, immunohistochemistry; $\mathrm{p}$-, phosphorylated; PERK, pancreatic endoplasmic reticulum kinase. 

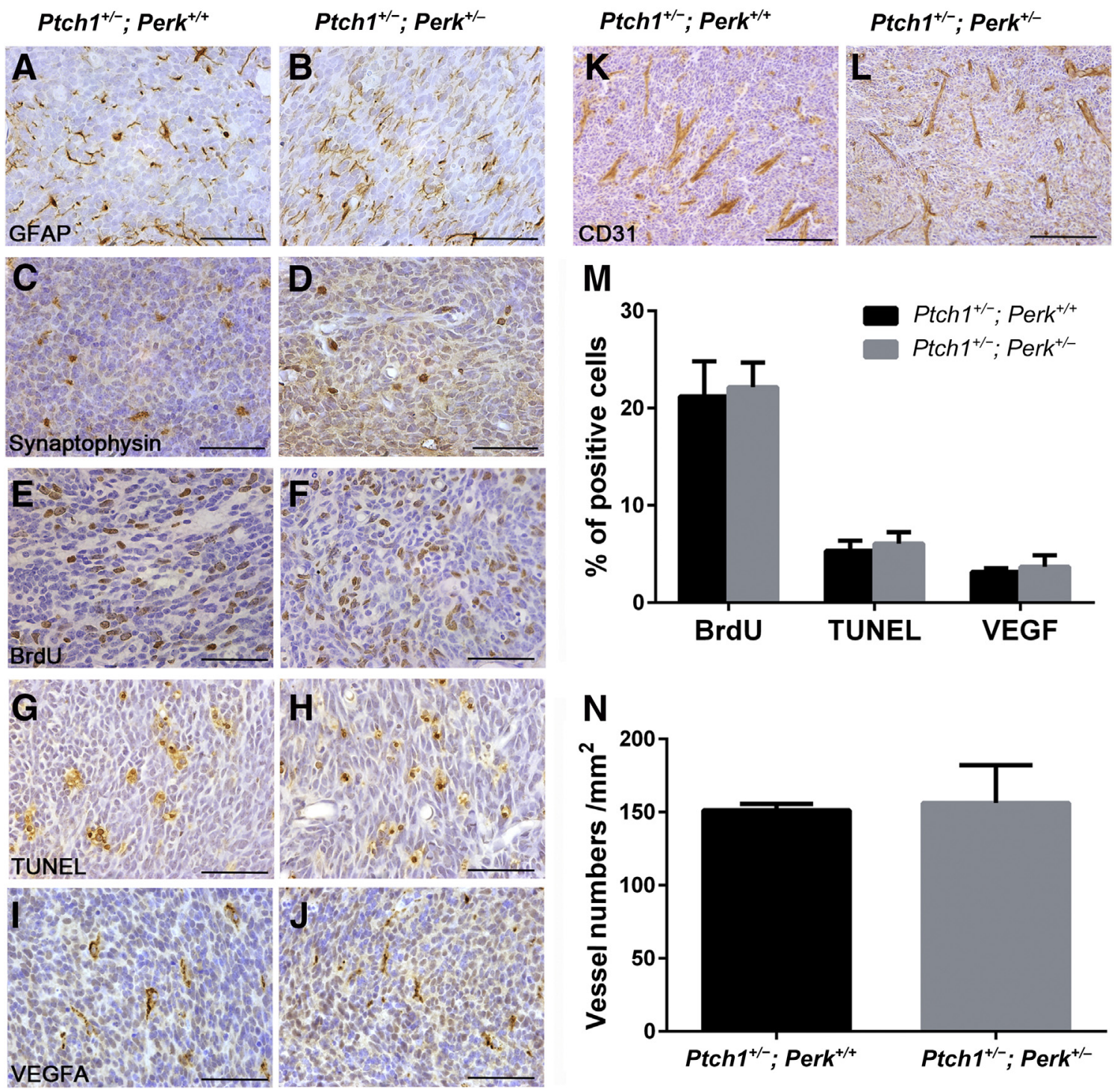

Figure 5 PERK heterozygous deficiency did not affect cell proliferation, cell apoptosis, or angiogenesis in medulloblastomas in adult $P$ tch $1^{+/-}$mice. A and B: GFAP IHC found that PERK heterozygous deficiency did not change the expression pattern of GFAP in medulloblastomas in adult Ptch1 ${ }^{+/-}$mice. $\mathbf{C}$ and $\mathbf{D}$ : Synaptophysin IHC found that PERK heterozygous deficiency did not change the expression pattern of synaptophysin in medulloblastomas in adult Ptch $1^{+/-}$mice. E, F, and M: BrdU labeling revealed comparable number of proliferating cells in medulloblastomas in adult Ptch $1^{+/-} ;$Perk $^{+/+}$mice and Ptch ${ }^{+/-}$; Perk ${ }^{+/-}$mice. G, H, and M: TUNEL staining revealed comparable number of apoptotic cells in medulloblastomas in adult Ptch $1^{+/-} ;$Perk $^{+/+}$mice and Ptch $1^{+/-} ; P_{\text {erk }}{ }^{+/-}$

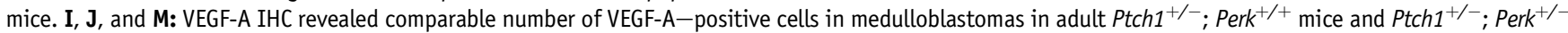
mice. K, L, and N: CD31 IHC revealed comparable number of blood vessels in medulloblastomas in adult Ptch1 ${ }^{+/-} ;$Perk $^{+/+}$mice and Ptch1 ${ }^{+/-} ;$Perk ${ }^{+/-}$mice. Data are expressed as means \pm SD. $n=4$ animals. Scale bars: $50 \mu \mathrm{m}(\mathbf{A}-\mathbf{J}) ; 100 \mu \mathrm{m}$ (K and L). BrdU, bromodeoxyuridine; CD31, cluster of differentiation 31; GFAP, glial fibrillary acidic protein; IHC, immunohistochemistry; PERK, pancreatic endoplasmic reticulum kinase; TUNEL, terminal deoxynucleotidyl transferasemediated biotinylated UTP nick end labeling; VEGF-A, vascular endothelial growth factor A.

6-week-old PtchI ${ }^{+/-} ;$Perk $^{+/-}$mice compared with PtchI ${ }^{+/}$; Perk $^{+/+}$mice (Figure 7, C and D). BrdU labeling (Figure 7, E, F, and K) and PCNA IHC (data not shown) found that PERK heterozygous deficiency did not significantly alter the rate of cell proliferation in diffuse hyperplastic lesions in 6-week-old Ptch1 ${ }^{+/}$mice. Importantly, TUNEL labeling found that PERK heterozygous deficiency significantly increased the number of apoptotic cells in diffuse hyperplastic lesions in 6-week-old $P t c h 1^{+/-}$ mice (Figure 7, G, H, and L). Active-caspase 3 IHC also found that the number of apoptotic cells were significantly increased in diffuse hyperplastic lesions in 6-week-old Ptchl ${ }^{+/-} ;$Perk $^{+/-}$mice compared with Ptchl $^{+/-} ;$Perk $^{+/+}$ mice (Figure 7, I, J, and M). However, there were noticeably fewer active-caspase 3-positive cells than TUNEL-positive cells in corresponding lesions. This discrepant result likely reflects that TUNEL labeling is a more sensitive method to detect cell apoptosis in diffuse hyperplastic lesions than active-caspase 3 IHC. Collectively, these data suggest that PERK haploinsufficiency enhances premalignant GCP apoptosis in diffuse hyperplastic lesions in the cerebellum of $\mathrm{PtchI}^{+/-}$mice during 


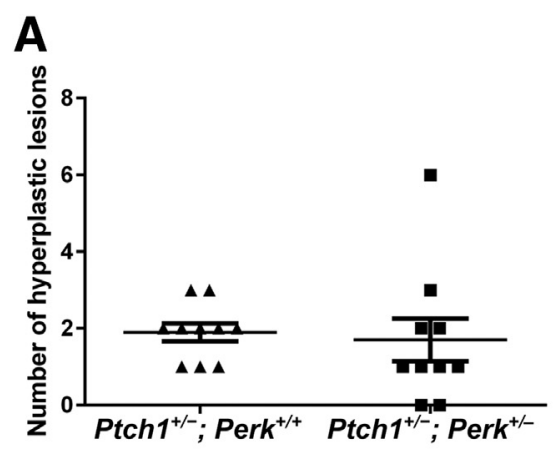

B

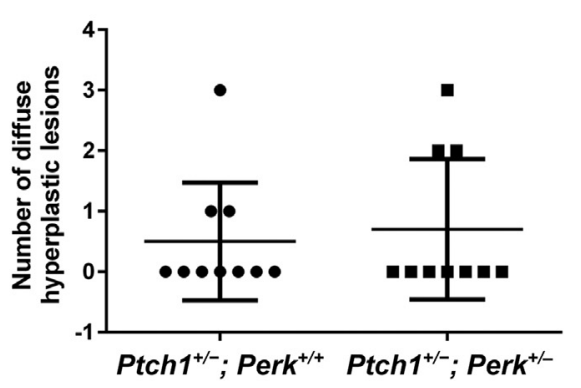

Figure 6 PERK heterozygous deficiency did not reduce the number of the cerebellar hyperplastic lesions in young Ptch $1^{+/-}$mice. A: The scatter plot shows that PERK heterozygous deficiency did not significantly change the number of total hyperplastic lesions in the cerebellum of 6-week-old Ptch $1^{+/-}$mice. B: The scatter plot shows that PERK heterozygous deficiency did not reduce the number of diffuse hyperplastic lesions in the cerebellum of 6-week-old Ptch1 $1^{+/-}$mice. Data are expressed as means \pm SD. $n=10$ mice. PERK, pancreatic endoplasmic reticulum kinase. malignant transformation of medulloblastoma. As described in PERK Haploinsufficiency Reduces the Incidence of Medulloblastomas in Ptch $1^{+1-}$ Mice, we found that PERK haploinsufficiency reduced the incidence of medulloblastoma but had a minimal effect on tumor cells in adult $P t c h 1^{+/-}$ mice after malignant transformation. Taken together, our data indicate that PERK haploinsufficiency suppresses medulloblastoma development in $P t c h 1^{+/-}$mice by enhancing premalignant GCP apoptosis in diffuse hyperplastic lesions during the course of malignant transformation.

It was found that PERK activation attenuates the activity of the p53 pathway, the master regulator of apoptosis during malignant transformation. ${ }^{45,46}$ A previous report found that p53 deficiency increases the incidence and accelerates the development of medulloblastomas in $\mathrm{Ptchl}^{+/-}$mice. $^{47}$ Therefore, we were interested in the potential role of p53 in the proapoptotic effects of PERK haploinsufficiency on premalignant GCPs. p53 Immunostaining found immunoreactivity of p53 was noticeably increased in diffuse hyperplastic lesions in 6-week-old Ptchl $^{+/-}$; Perk $^{+/-}$mice compared with Ptchl $^{+/-} ;$Perk $^{+/+}$mice (Figure 7, N and O). PUMA, a Bcl-2 homology 3-only Bcl-2 family member, is a p53-responsive gene and a critical mediator of p53-induced apoptosis. ${ }^{48,49}$ Interestingly, PUMA immunostaining found that immunoreactivity of PUMA was markedly elevated in diffuse hyperplastic lesions in 6-week-old Ptch1 ${ }^{+/-} ;$Perk $^{+/-}$ mice compared with Ptchl $^{+/-} ;$Perk $^{+/+}$mice (Figure 7, P and Q). Collectively, these data suggest the possibility that PERK haploinsufficiency induces premalignant GCP apoptosis in diffuse hyperplastic lesions during the course of malignant transformation by increasing the activity of the p53-PUMA pathway.

\section{Discussion}

With the use of in vitro and xenograft models, recent studies suggest that PERK activation might promote malignancy by attenuating apoptosis during the course of cell transformation. $^{13,43}$ Although two previous papers indicate the inhibiting effects of PERK deficiency on tumor growth in genetically engineered mouse models, ${ }^{50,51}$ the promoting role of PERK signaling in malignant transformation has not been verified in animal models that faithfully resemble human tumors. Ptch1 $1^{+/-}$mice recapitulate human Gorlin's syndrome and are regarded as the best mouse model to study the mechanisms of malignant transformation of the SHH subgroup of medulloblastomas. ${ }^{21,23,24,44}$ With the use of this mouse model, herein, we provided compelling evidence that PERK activation promoted medulloblastoma development by attenuating premalignant GCP apoptosis during the course of malignant transformation. We showed that PERK signaling was activated in premalignant GCP in focal hyperplastic lesions and diffuse hyperplastic lesions in the cerebellum of young Ptch1 ${ }^{+/-}$mice, in medulloblastoma cells in adult Ptch $1^{+/-}$mice, and in medulloblastoma cells in human patients. We demonstrated that PERK haploinsufficiency reduced the incidence of medulloblastomas in Ptch1 ${ }^{+/-}$mice. Importantly, we found that PERK haploinsufficiency had a minimal effect on medulloblastoma cells in adult $P$ tch $1^{+/-}$mice after malignant transformation but significantly enhanced premalignant GCP apoptosis in diffuse hyperplastic lesions in young $P t c h 1^{+/-}$mice during malignant transformation.

Apoptosis is believed to serve as a natural barrier to malignancy. ${ }^{11,12}$ The transforming effects of oncogenes, which drive unrestrained cell proliferation, are countered by intrinsic apoptosis mechanisms, which are triggered in response to various physiologic stresses that cells experience during the course of malignant transformation. Recent studies report that ER stress is activated in cells during malignant transformation and that PERK activation in response to ER stress either facilitates the transformation by suppressing apoptosis or impairs the transformation by promoting apoptosis. ${ }^{13,15,43}$ In this study, we showed that PERK signaling was activated in premalignant GCPs in reversible hyperplastic lesions in the cerebellum of young Ptchl ${ }^{+/-}$mice and that PERK haploinsufficiency enhanced premalignant GCP apoptosis and reduced tumor incidence in these mice. Thus, our data suggest that PERK signaling promotes medulloblastoma tumorigenesis by circumventing apoptosis during the transformation of GCPs. It is generally believed that activation of PERK signaling preserves cell viability under stressful conditions through inhibition of global protein biosynthesis and induction of certain stressinduced cytoprotective genes. ${ }^{2,3}$ Several studies report that PERK activation attenuates the activity of the p53 pathway, the master regulator of apoptosis during malignant transformation. ${ }^{45,46}$ Loss-of-function mutations of p53 contribute 

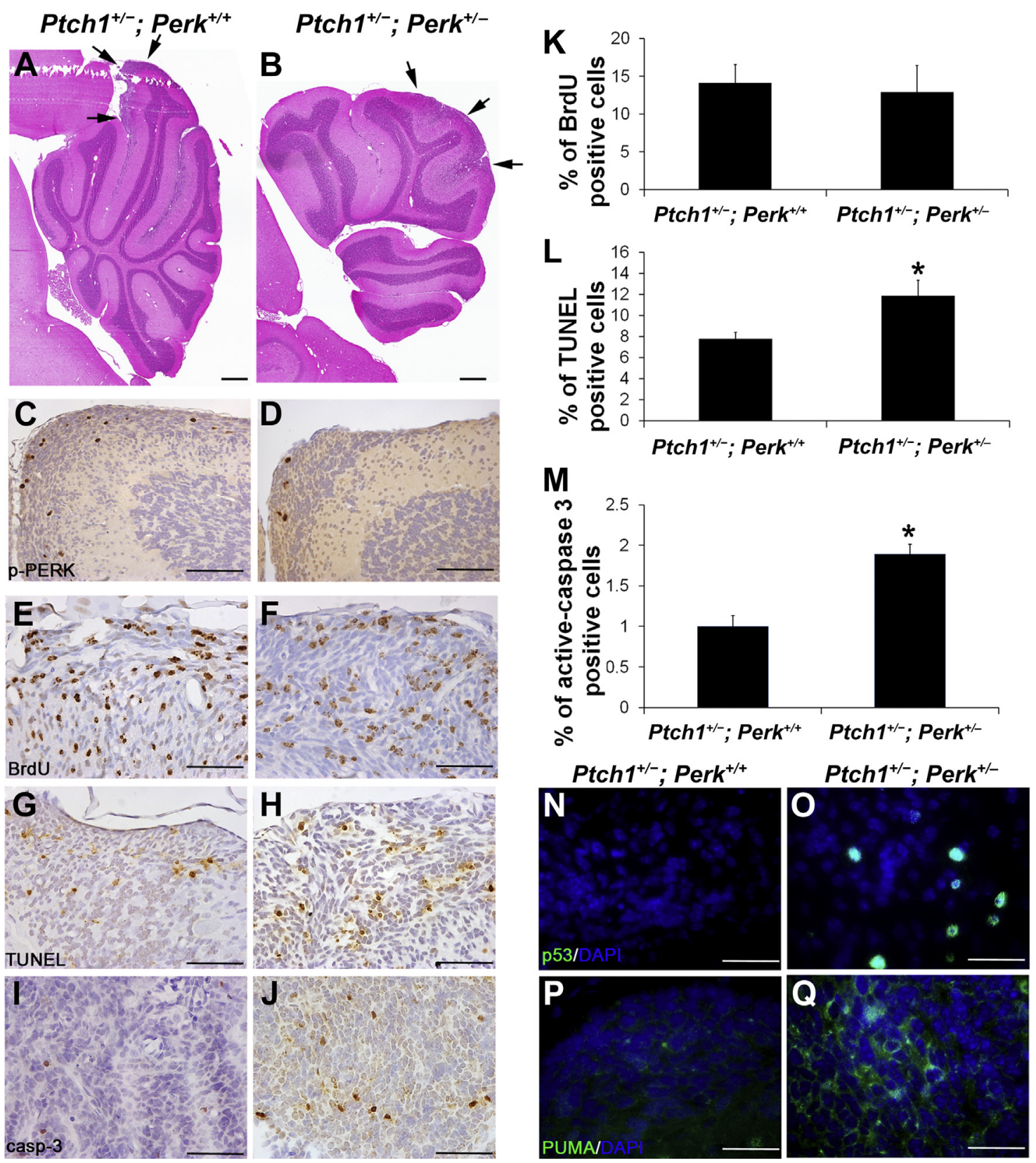

Figure 7 PERK heterozygous deficiency enhanced apoptosis of premalignant GCPs in diffuse hyperplastic lesions in the cerebellum of young Ptch1 ${ }^{+/-}$mice. A: H\&E staining revealed a diffuse hyperplastic lesion (arrow) in the cerebellum of 6-week-old Ptch $1^{+/-}$; Perk ${ }^{+/+}$mice. B: H\&E staining revealed a diffuse hyperplastic lesion (arrow) in the cerebellum of 6 -week-old $P$ tch $1^{+/-} ;$Perk ${ }^{+/-}$mice. $\mathbf{C}$ and D: $\mathrm{p}$-PERK IHC found noticeably decreased immunoreactivity of $\mathrm{p}$-PERK in diffuse hyperplastic lesions in 6-week-old Ptch $1^{+/-} ; P_{\text {erk }}^{+/-}$mice compared with Ptch $1^{+/-} ;$Perk ${ }^{+/+}$mice. E, F, and K: BrdU labeling revealed comparable number of proliferating cells in diffuse hyperplastic lesions in 6-week-old $P$ tch $1^{+/-} ;$Perk ${ }^{+/+}$mice and $P$ tch $1^{+/-} ;$Perk ${ }^{+/-}$mice. G, H, and L: TUNEL staining revealed significantly increased number of apoptotic cells in diffuse hyperplastic lesions in 6-week-old Ptch1 $1^{+/-} ;$Perk $^{+/-}$mice compared with Ptch1 ${ }^{+/-} ;$Perk ${ }^{+/+}$mice. I, J, and M: Active-caspase 3 IHC revealed significantly increased number of apoptotic cells in diffuse hyperplastic lesions in 6 -week-old Ptch1 ${ }^{+/-}$; Perk ${ }^{+/-}$mice compared with $P$ tch $1^{+/-}$; Perk ${ }^{+/+}$mice. $\mathbf{N}$ and $\mathbf{0}$ : p53 Immunostaining revealed noticeably increased expression of p53 in diffuse hyperplastic lesions in 6-weekold Ptch $1^{+/}$; Perk ${ }^{+/-}$mice compared with Ptch $1^{+/-}$; Perk ${ }^{+/+}$mice. $\mathbf{P}$ and Q: PUMA immunostaining revealed noticeably increased expression of PUMA in diffuse hyperplastic lesions in 6-week-old Ptch $1^{+/-}$; Perk ${ }^{+/-}$mice compared with $P$ tch $1^{+/-}$; Perk ${ }^{+/+}$mice. Data are expressed as means \pm SD. $n=3$ animals. ${ }^{*} P<0.05$. Scale bars: $1000 \mu \mathrm{m}(\mathbf{A}$ and $\mathbf{B}) ; 100 \mu \mathrm{m}(\mathbf{C}$ and $\mathbf{D}) ; 50 \mu \mathrm{m}(\mathbf{E}-\mathbf{J}) ; 32 \mu \mathrm{m}(\mathbf{N}-\mathbf{Q})$. BrdU, bromodeoxyuridine; GCP, granule cell precursor; H\&E, hematoxylin and eosin; IHC, immunohistochemistry; p-, phosphorylated; PERK, pancreatic endoplasmic reticulum kinase; PUMA, p53 up-regulated modulator of apoptosis; TUNEL, terminal deoxynucleotidyl transferase-mediated biotinylated UTP nick end labeling.

significantly to the tumorigenesis of many tumor types, including medulloblastoma. ${ }^{11,12}$ Approximately $10 \%$ of human medulloblastomas have mutations in p53. ${ }^{17,52}$ Moreover, p53 deficiency dramatically increases the incidence and accelerates the development of medulloblastomas in Ptch $1^{+/-}$mice. ${ }^{47}$ Interestingly, we showed here that the increased premalignant GCP apoptosis in diffuse hyperplastic lesions of Ptchl $^{+/-} ;$Perk $^{+/-}$mice was accompanied with the 
enhanced expression of p53 and PUMA. Therefore, there is a possibility that PERK signaling promotes medulloblastoma tumorigenesis through attenuation of premalignant GCP apoptosis by inhibiting the activity of the p53-PUMA pathway.

The PERK-eIF2 $\alpha$ pathway is a major regulator of cell viability during ER stress under various physiologic and pathologic conditions. ${ }^{2,3}$ As expected, we found that PERK heterozygous deficiency significantly attenuated the activity of the PERK-eIF $2 \alpha$ pathway in medulloblastoma cells in adult $P t c h 1^{+/}$mice. Surprisingly, TUNEL labeling found that PERK heterozygous deficiency had no significant effect on cell apoptosis in the tumor. Moreover, BrdU labeling and PCNA immunostaining found that PERK heterozygous deficiency did not alter cell proliferation in the tumor. Multiple cooperative mutations of oncogenes and oncosuppressor genes are necessary for tumorigenesis. It is generally believed that additional mutations of oncogenes or oncosuppressor genes, besides Ptchl heterozygous mutation, are required for medulloblastoma tumorigenesis in Ptch1 ${ }^{+/-}$mice. ${ }^{23,44,53}$ The diminished impact of PERK haploinsufficiency on medulloblastoma cell viability, compared with its proapoptotic effect on premalignant GCPs in diffuse hyperplastic lesions, suggests that the tumor cells in Ptchl $^{+/-}$; Perk ${ }^{+/-}$mice gain additional mutations or epigenetic changes that compensate or overcome the deficiency of the PERK-eIF2 $\alpha$ pathway.

Data from in vitro studies and xenograft models suggest that PERK activation enhances tumor angiogenesis by inducing VEGF-A expression. ${ }^{42,54}$ In vitro studies from our laboratory and other groups found that PERK activation enhances VEGF-A expression in human medulloblastoma cells. ${ }^{26,55}$ Our previous study also suggests that inactivation of GADD34, a regulatory subunit of a phosphatase complex that dephosphorylates eIF $2 \alpha$, enhances the activity of the PERK-eIF $2 \alpha$ pathway and may facilitate medulloblastoma formation in the cerebellum of transgenic mice that express the immune cytokine interferon- $\gamma$ in the central nervous system by promoting angiogenesis through induction of VEGF-A. ${ }^{29}$ Moreover, a report indicates that PERK deficiency attenuates tumor cell proliferation and angiogenesis in $\beta$-cell insulinomas in transgenic mice that express the SV40 large T-antigen specifically in $\beta$ cells. ${ }^{50}$ In contrast, another report indicates that PERK deficiency delays tumor development but has no important effect on angiogenesis in mammary adenocarcinoma in transgenic mice that express oncogene Neu specifically in mammary epithelium. $^{51}$ We showed here that PERK haploinsufficiency reduced the incidence of medulloblastomas in $P t c h 1^{+/-}$mice but did not affect VEGF-A expression or angiogenesis in the tumor. Collectively, these data likely suggest that the promoting effects of PERK signaling on VEGF-A expression and/or tumor angiogenesis are not ubiquitous, possibly determined by genetic mutations or epigenetic changes in individual molecular subtypes of tumors.

\section{Conclusions}

With the use of $P t c h 1^{+/-}$mice, the results presented in this study suggest that PERK activation contributes to medulloblastoma development through inhibition of premalignant GCP apoptosis during the course of malignant transformation. This work represents the first experimental demonstration of a link between PERK activation and malignant transformation in an animal model that faithfully resembles human tumor. Moreover, we demonstrated PERK activation in human medulloblastoma. Unfortunately, human samples do not afford an opportunity to study the early stages of tumor development, but the persistence of PERK signaling is also consistent with a pervasive role in medulloblastoma tumorigenesis.

\section{Supplemental Data}

Supplemental material for this article can be found at http://dx.doi.org/10.1016/j.ajpath.2016.03.004.

\section{References}

1. Harding HP, Zhang Y, Ron D: Protein translation and folding are coupled by an endoplasmic-reticulum-resident kinase. Nature 1999, 397:271-274

2. Marciniak SJ, Ron D: Endoplasmic reticulum stress signaling in disease. Physiol Rev 2006, 86:1133-1149

3. Tabas I, Ron D: Integrating the mechanisms of apoptosis induced by endoplasmic reticulum stress. Nat Cell Biol 2011, 13:184-190

4. Hetz C: The unfolded protein response: controlling cell fate decisions under ER stress and beyond. Nat Rev Mol Cell Biol 2012, 13:89-102

5. Bi M, Naczki C, Koritzinsky M, Fels D, Blais J, Hu N, Harding H, Novoa I, Varia M, Raleigh J, Scheuner D, Kaufman RJ, Bell J, Ron D, Wouters BG, Koumenis C: ER stress-regulated translation increases tolerance to extreme hypoxia and promotes tumor growth. EMBO J 2005, 24:3470-3481

6. Moenner M, Pluquet O, Bouchecareilh M, Chevet E: Integrated endoplasmic reticulum stress responses in cancer. Cancer Res 2007, 67:10631-10634

7. Ranganathan AC, Ojha S, Kourtidis A, Conklin DS, AguirreGhiso JA: Dual function of pancreatic endoplasmic reticulum kinase in tumor cell growth arrest and survival. Cancer Res 2008, 68: 3260-3268

8. Mujcic H, Nagelkerke A, Rouschop KM, Chung S, Chaudary N, Span PN, Clarke B, Milosevic M, Sykes J, Hill RP, Koritzinsky M, Wouters BG: Hypoxic activation of the PERK/eIF2 $\alpha$ arm of the unfolded protein response promotes metastasis through induction of LAMP3. Clin Cancer Res 2013, 19:6126-6137

9. Ma Y, Hendershot LM: The role of the unfolded protein response in tumour development: friend or foe? Nat Rev Cancer 2004, 4: 966-977

10. Vandewynckel YP, Laukens D, Geerts A, Bogaerts E, Paridaens A, Verhelst X, Janssens S, Heindryckx F, Van Vlierberghe H: The paradox of the unfolded protein response in cancer. Anticancer Res 2013, 33:4683-4694

11. Hanahan D, Weinberg RA: The hallmarks of cancer. Cell 2000, 100: $57-70$

12. Hanahan D, Weinberg RA: Hallmarks of cancer: the next generation. Cell 2011, 144:646-674 
13. Hart LS, Cunningham JT, Datta T, Dey S, Tameire F, Lehman SL, Qiu B, Zhang H, Cerniglia G, Bi M, Li Y, Gao Y, Liu H, Li C, Maity A, Thomas-Tikhonenko A, Perl AE, Koong A, Fuchs SY, Diehl JA, Mills IG, Ruggero D, Koumenis C: ER stress-mediated autophagy promotes Myc-dependent transformation and tumor growth. J Clin Invest 2012, 122:4621-4634

14. Dey S, Tameire F, Koumenis C: PERK-ing up autophagy during MYC-induced tumorigenesis. Autophagy 2013, 9:612-614

15. Huber AL, Lebeau J, Guillaumot P, Pétrilli V, Malek M, Chilloux J, Fauvet F, Payen L, Kfoury A, Renno T, Chevet E, Manié SN: p58(IPK)-mediated attenuation of the proapoptotic PERK-CHOP pathway allows malignant progression upon low glucose. Mol Cell 2013, 49:1049-1059

16. Crawford JR, MacDonald TJ, Packer RJ: Medulloblastoma in childhood: new biological advances. Lancet Neurol 2007, 6:1073-1085

17. Northcott PA, Jones DT, Kool M, Robinson GW, Gilbertson RJ, Cho YJ, Pomeroy SL, Korshunov A, Lichter P, Taylor MD, Pfister SM: Medulloblastomics: the end of the beginning. Nat Rev Cancer 2012, 12:818-834

18. Taylor MD, Northcott PA, Korshunov A, Remke M, Cho YJ, Clifford SC, Eberhart CG, Parsons DW, Rutkowski S, Gajjar A, Ellison DW, Lichter P, Gilbertson RJ, Pomeroy SL, Kool M, Pfister SM: Molecular subgroups of medulloblastoma: the current consensus. Acta Neuropathol 2012, 123:465-472

19. Pugh TJ, Weeraratne SD, Archer TC, Pomeranz Krummel DA, Auclair D, Bochicchio J, et al: Medulloblastoma exome sequencing uncovers subtype-specific somatic mutations. Nature 2012, 488: $106-110$

20. Goodrich LV, Milenković L, Higgins KM, Scott MP: Altered neural cell fates and medulloblastoma in mouse patched mutants. Science 1997, 277:1109-1113

21. Corcoran RB, Scott MP: A mouse model for medulloblastoma and basal cell nevus syndrome. J Neurooncol 2001, 53:307-318

22. Oliver TG, Read TA, Kessler JD, Mehmeti A, Wells JF, Huynh TT, Lin SM, Wechsler-Reya RJ: Loss of patched and disruption of granule cell development in a pre-neoplastic stage of medulloblastoma. Development 2005, 132:2425-2439

23. Corcoran RB, Bachar Raveh T, Barakat MT, Lee EY, Scott MP: Insulin-like growth factor 2 is required for progression to advanced medulloblastoma in patched1 heterozygous mice. Cancer Res 2008, 68:8788-8795

24. Farioli-Vecchioli S, Cinà I, Ceccarelli M, Micheli L, Leonardi L, Ciotti MT, De Bardi M, Di Rocco C, Pallini R, Cavallaro S, Tirone F: Tis21 knock-out enhances the frequency of medulloblastoma in Patched1 heterozygous mice by inhibiting the Cxcl3-dependent migration of cerebellar neurons. J Neurosci 2012, 32:15547-15564

25. Robinson G, Parker M, Kranenburg TA, Lu C, Chen X, Ding L, et al: Novel mutations target distinct subgroups of medulloblastoma. Nature 2012, 488:43-48

26. Jamison S, Lin Y, Lin W: Pancreatic endoplasmic reticulum kinase activation promotes medulloblastoma cell migration and invasion through induction of vascular endothelial growth factor A. PLoS One 2015, 10:e0120252

27. Harding HP, Zeng H, Zhang Y, Jungries R, Chung P, Plesken H, Sabatini DD, Ron D: Diabetes mellitus and exocrine pancreatic dysfunction in Perk-/- mice reveals a role for translational control in secretory cell survival. Mol Cell 2001, 7:1153-1163

28. Committee for the Update of the Guide for the Care and Use of Laboratory Animals; National Research Council: Guide for the Care and Use of Laboratory Animals: Eighth Edition. Washington, DC, National Academies Press, 2011

29. Lin W, Lin Y, Li J, Harding HP, Ron D, Jamison S: A deregulated integrated stress response promotes interferon- $\gamma$-induced medulloblastoma. J Neurosci Res 2011, 89:1586-1595

30. Lin W, Kemper A, McCarthy KD, Pytel P, Wang JP, Campbell IL, Utset MF, Popko B: Interferon-gamma induced medulloblastoma in the developing cerebellum. J Neurosci 2004, 24:10074-10083
31. Lin Y, Huang G, Jamison S, Li J, Harding HP, Ron D, Lin W: PERK activation preserves the viability and function of remyelinating oligodendrocytes in immune-mediated demyelinating diseases. Am J Pathol 2014, 184:507-519

32. Lin W, Harding HP, Ron D, Popko B: Endoplasmic reticulum stress modulates the response of myelinating oligodendrocytes to the immune cytokine interferon-gamma. J Cell Biol 2005, 169: 603-612

33. Lin $\mathrm{Y}$, Jamison $\mathrm{S}$, Lin $\mathrm{W}$ : Interferon- $\gamma$ activates nuclear factor- $\kappa \mathrm{B}$ in oligodendrocytes through a process mediated by the unfolded protein response. PLoS One 2012, 7:e36408

34. Wechsler-Reya R, Scott MP: The developmental biology of brain tumors. Annu Rev Neurosci 2001, 24:385-428

35. Hatten ME, Roussel MF: Development and cancer of the cerebellum. Trends Neurosci 2011, 34:134-142

36. Kim JY, Nelson AL, Algon SA, Graves O, Sturla LM, Goumnerova LC, Rowitch DH, Segal RA, Pomeroy SL: Medulloblastoma tumorigenesis diverges from cerebellar granule cell differentiation in patched heterozygous mice. Dev Biol 2003, 263: 50-66

37. Thomas WD, Chen J, Gao YR, Cheung B, Koach J, Sekyere E, Norris MD, Haber M, Ellis T, Wainwright B, Marshall GM: Patched1 deletion increases $\mathrm{N}-\mathrm{Myc}$ protein stability as a mechanism of medulloblastoma initiation and progression. Oncogene 2009, 28: $1605-1615$

38. Fults DW: Modeling medulloblastoma with genetically engineered mice. Neurosurg Focus 2005, 19:E7

39. Lin W, Bailey SL, Ho H, Harding HP, Ron D, Miller SD, Popko B: The integrated stress response prevents demyelination by protecting oligodendrocytes against immune-mediated damage. J Clin Invest 2007, 117:448-456

40. Wang L, Popko B, Roos RP: The unfolded protein response in familial amyotrophic lateral sclerosis. Hum Mol Genet 2011, 20: $1008-1015$

41. Lin W, Kemper A, Dupree JL, Harding HP, Ron D, Popko B: Interferon-gamma inhibits central nervous system remyelination through a process modulated by endoplasmic reticulum stress. Brain 2006, 129:1306-1318

42. Atkins C, Liu Q, Minthorn E, Zhang SY, Figueroa DJ, Moss K, Stanley TB, Sanders B, Goetz A, Gaul N, Choudhry AE, Alsaid H, Jucker BM, Axten JM, Kumar R: Characterization of a novel PERK kinase inhibitor with antitumor and antiangiogenic activity. Cancer Res 2013, 73:1993-2002

43. Feng YX, Sokol ES, Del Vecchio CA, Sanduja S, Claessen JH, Proia TA, Jin DX, Reinhardt F, Ploegh HL, Wang Q, Gupta PB: Epithelial-to-mesenchymal transition activates PERK-eIF2 $\alpha$ and sensitizes cells to endoplasmic reticulum stress. Cancer Discov 2014, 4:702-715

44. Mille F, Tamayo-Orrego L, Lévesque M, Remke M, Korshunov A, Cardin J, Bouchard N, Izzi L, Kool M, Northcott PA, Taylor MD, Pfister SM, Charron F: The Shh receptor Boc promotes progression of early medulloblastoma to advanced tumors. Dev Cell 2014, 31: $34-47$

45. Qu L, Huang S, Baltzis D, Rivas-Estilla AM, Pluquet O, Hatzoglou M, Koumenis C, Taya Y, Yoshimura A, Koromilas AE: Endoplasmic reticulum stress induces p53 cytoplasmic localization and prevents p53-dependent apoptosis by a pathway involving glycogen synthase kinase-3beta. Genes Dev 2004, 18:261-277

46. Baltzis D, Pluquet O, Papadakis AI, Kazemi S, Qu LK, Koromilas AE: The eIF2alpha kinases PERK and PKR activate glycogen synthase kinase 3 to promote the proteasomal degradation of p53. J Biol Chem 2007, 282:31675-31687

47. Wetmore C, Eberhart DE, Curran T: Loss of p53 but not ARF accelerates medulloblastoma in mice heterozygous for patched. Cancer Res 2001, 61:513-516

48. Yu J, Zhang L: PUMA, a potent killer with or without p53. Oncogene 2008, 27:S71-S83 
49. Hikisz P, Kiliańska ZM: PUMA, a critical mediator of cell death-one decade on from its discovery. Cell Mol Biol Lett 2012, 17:646-669

50. Gupta S, McGrath B, Cavener DR: PERK regulates the proliferation and development of insulin-secreting beta-cell tumors in the endocrine pancreas of mice. PLoS One 2009, 4:e8008

51. Bobrovnikova-Marjon E, Grigoriadou C, Pytel D, Zhang F, Ye J, Koumenis C, Cavener D, Diehl JA: PERK promotes cancer cell proliferation and tumor growth by limiting oxidative DNA damage. Oncogene 2010, 29:3881-3895

52. Parsons DW, Li M, Zhang X, Jones S, Leary RJ, Lin JC, et al: The genetic landscape of the childhood cancer medulloblastoma. Science 2011, 331:435-439
53. Pazzaglia S, Tanori M, Mancuso M, Gessi M, Pasquali E, Leonardi S, Oliva MA, Rebessi S, Di Majo V, Covelli V, Giangaspero F, Saran A: Two-hit model for progression of medulloblastoma preneoplasia in Patched heterozygous mice. Oncogene 2006, 25:5575-5580

54. Pereira ER, Frudd K, Awad W, Hendershot LM: Endoplasmic reticulum (ER) stress and hypoxia response pathways interact to potentiate hypoxia-inducible factor 1 (HIF-1) transcriptional activity on targets like vascular endothelial growth factor (VEGF). J Biol Chem 2014, 289:3352-3364

55. Pereira ER, Liao N, Neale GA, Hendershot LM: Transcriptional and post-transcriptional regulation of proangiogenic factors by the unfolded protein response. PLoS One 2010, 5:e12521 